\title{
First Issues, first Words: Vision in the Making
}

\author{
JESSICA BARNESS ${ }^{1}$
}

1. Kent State University, Kent, Ohio, USA

SUGGESTED CITATION: Barness, J. “First Issues, First Words: Vision in the Making.” Dialectic, 1.1 (2016): pgs. 39-60. DOI: http:// dx.doi.org/10.3998/dialectic.14932326.0001.105

\section{Abstract}

This study connects design history with design practice, and focuses on editorial introductions found within the first issues of a broad cross section of design periodicals launched around the world between 1902-2015. This body of literature includes a diverse range of scholarly/peer-reviewed journals, professional magazines, and designer-authored publications. All of these are somehow connected with visual communication design and related disciplines. Many design periodicals began publication to provide or facilitate thought leadership, criticism, research or scholarly inquiry within particular social, economic, and industrial contexts. Their introductory issues, and often the editorial mission statements contained within them, may be read as calls to action, or manifestos, among the various constituencies of the professional or academic design communities, or their clienteles, or among the broad array of vendors and manufacturers that the work of designers affects. As a means to critically examine these writings on what design is, does, and might be, this author prototyped a 'new' text, with lines extracted from these introductions. The resulting new text, Vision in the Making, makes visible a collection of design writings that contain informational as well as expressive content, and may not otherwise receive close attention. In this paper, this study's context and method are followed by Vision in the Making in the form of a visual essay.

\section{Keywords}

design history, design practice, design

periodicals, manifesto, prototype 



\section{First Issues, First Words:}

Vision in the Making

JESSICA BARNESS

\section{Introduction}

Some theoretical approaches to thinking about design and methods for designing begin quietly, while others roar into existence. In design writing, the definitive boundary that separates a 'manifesto' from an 'editorial' is often a matter of context, and intent. Published visionary statements are familiar territory for designers, and any one particular 'design manifesto' can mark the emergence or affirmation of a seminal (or trivial) design movement. Many of these focus attention on issues of design practice, and are written with a distinct social function toward bringing a community of like-minded individuals together. The word manifesto is akin to manifestation, which is to embody a theory or idea. Design manifestos of note include William Morris' The Arts and Crafts of To-Day (1889); Adolf Loos' Ornament and Crime (1910); Walter Gropius' Bauhaus Manifesto (1919); Naum Gabo and Antoine Pevsner's Constructivist Manifesto (1920); El Lissitzky's Topography of Typography (1923); Ken Garland's First Things First (1964, 2014); Dieter Rams' Ten Rules of Good Design (1987); Icograda's Design Education Manifesto (2000, 2011); Ellen Lupton's Free Font Manifesto (2006); and Allan Chochinov's 1000 Words: A Manifesto for Sustainability in Design (2007). Through these statements, practitioners, educators, and

Vignelli, M. "Keynote Address." In Coming of Age: The First Symposium on the History of Graphic Design, April 20-21, 1983, Rochester Institute of Technology, edited by $B$. Hodik \& R. Remington, p. 11. Rochester, NY, USA: Rochester Institute of Technology, 1985. scholars identify and often assert a shift in the scope and focus of the work that transpires within and around their communities. Practice - an act of manifesting - is one of the crucial defining points of design, and the poetics of these activities serve to inform the construction of who we are. Without them, we'd be "just a continuous stream of little designers". "

Within the context of 'affirmative manifestations,' I began studying a lineage of design periodicals launched from 1902-2015. This body of literature 
an a methodological note, the main challenge encountered throughout this study was accessibility: academic journals can generally be searched through a library database, but older issues of professional magazines and designer-authored publications are more difficult to obtain. includes a diverse range of scholarly/peer-reviewed journals, professional magazines, and designer-authored publications, and these are all connected to communication design and related fields. ${ }^{\text {a }}$ Specifically, I began reading through editors' introductions within the first issues of these publications. Here could be found the presence of cautiously assertive yet authoritative voices. Very often when there is a shift or debut of authority, something new ignites; these first words, written by editors and sometimes referred to as 'letters,' often read as calls to action.

Occupying a space between scholarly advocacy, professional correspondence, and manifesto, these texts hold a curious position within the greater scheme of periodical publication and within design history. They also serve to introduce a long-term project of mine that has been taking shape over countless hours (days, months, years...) of critiquing, curating, organizing, selecting, and authoring. These essays may be omitted from tables of contents and not referenced in other literature. Their authorship may be credited to named persons, initials, or simply “The Editors.” In asserting a conceptual framework for the future and setting the public tone for a new periodical, they provide written evidence of new voices, new directions, and new goals for design. Pushing for change, an editor's first words are not quite research or practice, but they are certainly evidence of lived experience, and they reflect a critical observation of a discipline or field.

This study focuses on my investigation of a history of design through a critical review and re-contextualization of inaugural, publication-based reflections on design practice. This experiential framing offers a new way to understand what design is, does, and might be. It begins with an overview of English-language design periodicals situated within a historiographic framework. This is followed by observations about the meta-subjectivity, visual characteristics and linguistic variations found in these types of publications. I then document and reflect on a 'prototyping' process for cut-and-paste design practice in which I use extracted lines of text from first-issue editorial introductions to compose a new text. The result, Vision in the Making, is presented as an intertextual composition - a 'manifesto' made manifest in the form of a visual essay.

\section{Design Periodicals}

In the early twentieth century, writing in graphic design, advertising or commercial art periodicals in North America and western Europe lived largely 
under the guise of commercial art or graphic arts, and circulated through trade magazines. Monotype, a supplier of typesetting machinery and typefaces for the industry, began publishing The Monotype Recorder and Monthly Circular in 1902 (relaunched in 2014 as The Recorder). Popular wwII era trade periodicals Print (1940) and Graphis (1944), and, eventually, the Journal of Commercial Art (1959, later published as Communication Arts), served to elevate the importance of professional practice and provide information and news for the industry. More periodicals that reported on or critically analyzed issues in and around graphic design practice and criticism appeared over the next few decades. Among these, just two years after First Things First was published in 1964, Dot Zero (1966) was launched to integrate visual communication design practice with theory and criticism, and, the next year, the Journal of Typographic Research (1967) began publication and focused on the scholarly investigation of typography (later published as Visible Language, now the oldest peer-reviewed design journal in the world). Neither was a traditional graphic arts magazine and both introduced new ways to write critically and analytically about design (and to explore the visual design of writing). Shortly thereafter in 1971, Icographic was launched by the international design organization Icograda, followed by professional typography magazines U\&lc (1973) and Baseline (1979). In 1982, the Journal of Art and Design Education began publication, and in 1984 - the same year the Apple computer made its grand debut - the academic journal Design Issues and the designer-authored magazine Emigre published their first issues. Though aimed at different audiences, all three of these were interested in changing the landscape of design through the introduction and analysis of form and the essential ideas that guided formal configurations, as well as through criticism and a variety of types of editorial, scholarly, and research writing. The following years gave way to a flurry of periodicals, from Fuse (1991) to Design Philosophy Papers (2003) to Shè Jì (2015), and it became clear that different aspects of the growing knowledge base of and about design were being introduced within each title. These all began within a certain span of time and place, and in response to new practices, the need to examine graphic design through new theoretical lenses, and, sometimes, through new types of media.

Emerging from diverse social, economic, and industry contexts, design periodicals represent attitudes toward practices related to or embedded within a typology that includes but is not limited to visual communications, graphic design, industrial design, architecture, interior design, interaction 
Editors. "Welcome." How, 1.1

(1985): p. 19.

3

Johnston, S., Holt, M., Burke, M.,

\& Muir, H. “86.1." Octavo, 1

(1986): n.p.

4

Margolin, V. “Editorial." Design

Issues, 1.1 (1984): p. 3. Online. Available at: http://www.jstor. org/stable/1511538 (Accessed 20 September 2016).

\section{5}

Dilnot, C. "The State of Design History, Part I: Mapping the Field."

Design Issues, 1.1 (1984): p. 6.

Online. Available at: http://www. jstor.org/stable/1511539

(Accessed 20 September 2016).

6

Margolin, V. The Politics of the Artificial: Essays on Design and Design Studies. Chicago, IL, USA: University of Chicago Press, 2002 , p. 225 .

7

Margolin, The Politics of the Artificial,p. 191. design, typography, design history, material culture, design management, and now, with this inaugural publication of Dialectic, design education. Few definitive frameworks exist to categorize design periodicals according to the wide variety of discourses that now affect and are affected by design and the work of designers and their collaborators. They might be further sorted into types related to audiences (practicing designers or designers working in academia or design researchers), evaluative practices (editor reviewed or peer-reviewed), or content sources (designer-authored, commissioned, or submissions-based). The editor introductions I have chosen to examine address different facets of design and its discourses. For example, in the mid-1980s, three vastly different periodicals began publication: HOW was launched to provide industry professionals with "start-to-finish information and/or instructions that trace a project from concept, to production, to final costing;" " Octavo was conceptualized, published, and edited by the design practice $8 \mathrm{vo}$ to "investigate the way in which letterforms are used in the visual arts, poetry, architecture and the environment...[and] design education;" ${ }^{3}$ and the academic journal Design Issues was founded at the University of Illinois at Chicago by design faculty members who believed that "before the design profession becomes too concerned with conclusions, a place for ongoing deliberation must be established.” ${ }^{4}$ A common thread running through these introductions is the desire to serve and facilitate inquiry toward the professional practice of design.

Design periodicals are artifacts and activities. At the same time, they are also meta-artifacts in that they manifest writing about artifacts and activities in design. The variances among the periodicals in attitudes, contexts, and practice reflect historiographic challenges in that "defining and explaining design and what a designer does are dependent not only on immersion in design practice, but also on the ability to see this practice in both historical and social perspectives." ${ }^{5}$ The issues of periodicals - those addressed, and those of the paginated variety - are in continuous development. Design is difficult to define because it is constantly changing, which presents a problem: "How, then, can we establish a body of knowledge about something that has no fixed identity?;" ${ }^{\circ}$ indeed, discussing these publications solely within a comprehensive, chronological arrangement may, “...assert a continuity among objects and actions that are in reality discontinuous." " Similarly, discussing singular meanings of design artifacts is "...ignoring the fact that design is a process of representation. It represents political, economic, and cultural power and values within the different spaces occupied, through engagement with different 
Buckley, C. "Made in Patriarchy: Toward a Feminist Analysis of Women

and Design." Design Issues, 3.2 (1986): p. 10. Online. Available at: http://www.jstor.org/stable/1511480 (Accessed 20 September 2016).

\section{9}

Fallan, K. \& Lees-Maffei, G. “It's Personal: Subjectivity in Design History." Design and Culture, 7.1 (2015): p. 15. Online. Available at: http://www. tandfonline.com/doi/abs/ 10.2752/175470715X14153615623565 (Accessed 20 September 2016).

10

Gemser, G., de Bont, C., Hekkert, P., \& Friedman, K. “Quality perceptions of design journals: The design scholars' perspective." Design Studies, 33.1 (2012): pgs. 4-23. Online. Available at: http://dx.doi.org/10. 1016/j.destud.2011.09.001 (Accessed 20 September 2016).

\section{1}

Barness, ]. "Letters are Media, Words are Collage: Writing Images through A (Dis)Connected Twen-

ty-Six." Message, 2 (2015): pgs. 47-48. Online. Available at: http:// www. jessicabarness. com/papers/Barness_Disconnected26_Message2015.pdf (Accessed 20 September 2016).

${ }^{\mathrm{b}}$ Cut-up, in this context, describes writing that is composed by cutting, pasting, and arranging material from preexisting sources. subjects." ${ }^{8}$ In this study, language used in editorial introductions represents the vision or self-awareness of its writer(s), and is thus concretely tied to the new periodical's imagined or proposed future; this vision is integrated with the subject matter of the publication, as well as with the facilitation of its specific discourse. As a result, a problem is encountered in this study: given the rather subjective nature of editorial introductions, how might these texts be effectively studied to expose their humanistic qualities, as well as their critical observations on design? Discussion on subjectivity in design history suggests that artifacts speak and must be translated, but “...how far can we go in our translations of 'thing talk?' Where is the border between imaginative interpretation and sheer flight of fancy?” 9

\section{Inquiry through Critical Making}

A common element across design periodicals in their first issues is the existence of editorial 'calls to action.' An exhaustive list of titles is practically non-existent, but a critical examination of a recent study, ${ }^{10}$ combined with a cursory analysis of library databases and helpful colleagues provided a starting point. In total, 72 periodicals were surveyed, and 62 contained editorial introductions in their inaugural issues. Of these, 50 editorial introductions contained visionary or self-aware language. Visionary discourse contains powerful or imaginative ideas on what a future will or might be like, and self-aware statements by particular editors and producers display the editorial knowledge and awareness of the individual character and purpose of their particular design periodical, as well as its relative position within the "landscape" of other design periodicals.

To better understand and communicate my findings, I offer a first-issue text of a different kind: a new text prototyped with phrases extracted from these inaugural editorial introductions. The term 'prototyping' is used to describe the process of manifesting an idea through the construction of a preliminary model. In this case, a new cut-and-paste text was made to expose the types of visionary or self-aware language found within the inaugural writings. My approach combines social and historiographic inquiry with design practice. The decision to work this way follows my previous research on Dada language games, cut-up, ${ }^{b}$ and DJ remix approaches to inform a framework for creating new messages. ${ }^{11}$ However, rather than relying on elements of chance, this study involved close readings of the texts, followed by the deliberate extraction and arrangement of lines. This process of reading through cut-and-paste 


\section{2}

Baker, S. "A Poetics of Graphic Design?" Visible Language, 28.3 (1994): p. 255. Online. Available

at: http://search.proquest.com/ docview/1297966689? accountid=11835

(Accessed 20 September 2016).

\section{3}

Drucker, J. Figuring the Word: Essays on Books, Writing, and Visual Poetics. New York, NY, USA: Granary Press, 1998, p. 74 .

\section{4}

Ruecker, S. "A Brief Taxonomy of Prototypes for the Digital Humanities." Scholarly and Research Communication, 6.2 (2015): para.

7. Online. Available at: http:// src-online.ca/index.php/src/article/

view/222/415 (Accessed 20 September 2016). See also Boer, L. \& Donovan, J. 2012. "Provotypes for Participatory Innovation" in DIS 2012: Proceedings of the Designing Interactive Systems Conference, 11-15 June 2012, Newcastle, UK: ACM

press, 2012: pgs. 388-397. Online. Available at: http://dx.doi. org/10.1145/2317956.2318014 (Accessed 20 September 2016). writing connects with a broader call for “.... non-linear and more visual form of history-writing, which we should perhaps not balk at calling a poetics of graphic design." ${ }^{12}$ The construction of entire narratives using appropriated sources may be seen in books such as Woman's World made by Graham Rawle (2005) and Société Réaliste's The Best American Book of the 2oth Century designed by Project Projects (2014). As described by Johanna Drucker, literature written through appropriation displays “...a recognition of the fact that language lives in the world and thus has a life beyond the original intention of its first author." 13

In designing this new text, titled Vision in the Making, I deliberately draw attention to the existence of multiple editorial voices as founders, stewards, curators, and activists. These writings quietly expose the advances and shortcomings that have guided and are guiding scholarship and professional practices in and around design. This was approached as a provocative prototype, or 'provotype,' which is intended to “...challenge presuppositions, break down stereotypical understandings, and generally produce changes in the way people think about a particular topic or situation." ${ }^{14}$ Through its narrative and bibliography, Vision in the Making makes visible a collection of design writings that may not otherwise receive close attention. Photocopies, scans, and photographs of originals (figure 1) were used as raw material that guided cut-and-paste processes that made use of both paper and digital components. These originals varied greatly in quality, depending on the original printing method used to publish them, as well as the nature of their distribution. These materials eventually yielded a diverse array of high-resolution digital files, scans of faxed material, visually disintegrated reproductions, and digital snapshots. Some letterform touch-up was necessary to ensure legibility, but the typographic character of each text has been retained. The individual lines, representing the earnestness and humor found throughout the literature, are no longer situated within their respective periodicals and discourses. Instead, they are contextualized alongside - and connected linguistically, conceptually, and physically with - the first words from editorial writings that were published in other first issues.

Vision in the Making is historiographic because of the nature of its contents and ahistorical in terms of its design. My process, which was subjective in that my voice is present as the designer-composer, was guided by visionary and self-aware language and not by historical markers (figure 2). As the composer making this new text, it was impossible to distance myself from the content. 


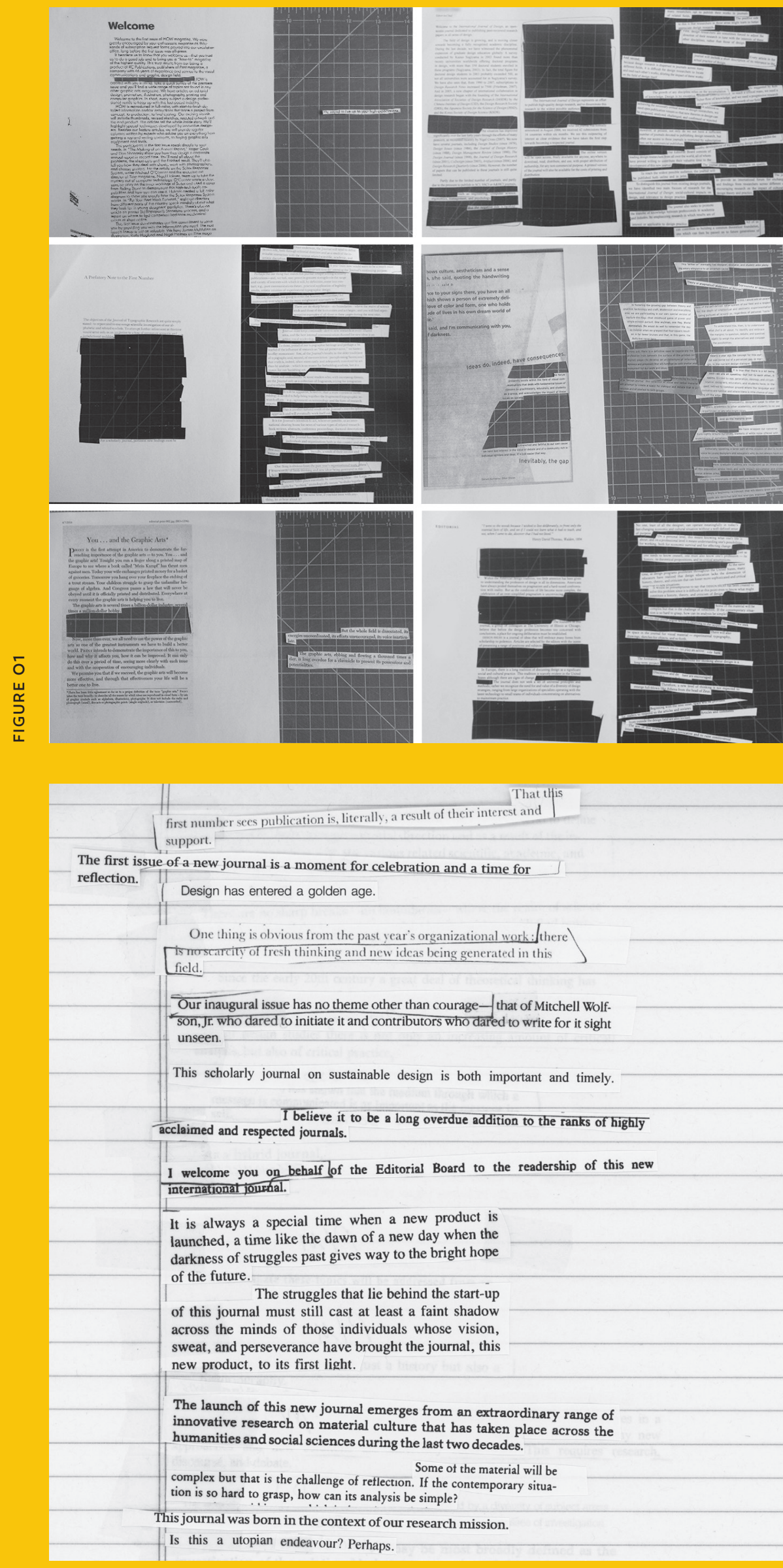



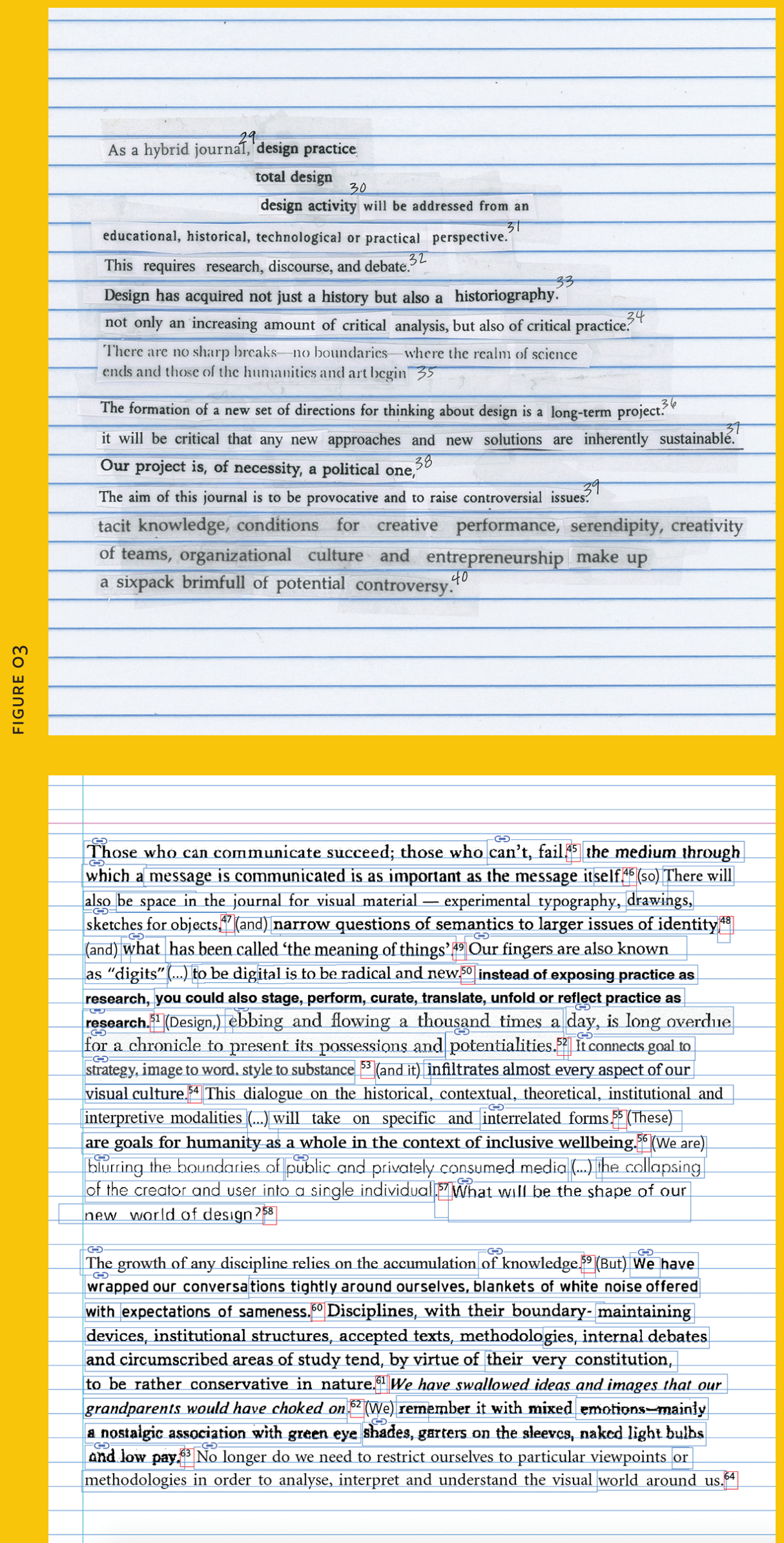
In order to craft a manifesto that could potentially speak to anyone (or everyone) connected with design, I sought to bridge issues and attitudes; by doing this, various lineages converge, and it becomes a tapestry of discourses. Power shifts between scholarly and professional concerns are purposefully merged. Though liberties were taken in juxtaposing and combining phrases, all sources are referenced, and the bibliography itself is an homage to authors, generations, and audiences (figure 3). Transition words were added and some pronouns replaced to build a more fluid reading experience. Specific periodical names are substituted with "our project" or similar. These paper iterations took final shape through digital composition (figure 4).

\section{Observations}

Through this study, a number of observations emerged regarding visual character and use of language. These form a starting point for future in-depth analysis of and about these periodicals.

Visually, the texts may be described across a spectrum of graphic character. At one end of this spectrum is the editor introduction for the Journal of Interior Design Education and Research (1975), which “...has no budget whatever" and was begun as a response to "... no noticeable lack of serious and scholarly work addressed specifically to problems of the profession." ${ }^{15}$ Its appearance suggests it was produced manually with a typewriter for a small community, was low-budget, and was without graphic embellishment of any kind. At the opposite end of the spectrum is Zed (1994), with its playful and rhythmic layout, a publication that sought to "identify and embrace the margins; to question, debate, and question again; to weigh the alternatives and consider the possibilities." ${ }^{16}$ Its use of slightly distorted typefaces throughout the various layouts that constituted its seven issues, combined with formal imperfections (representative of 1990s typographic layout trends that themselves referenced American typographic layout trends from the 1930s fostered by the likes of Brodovitch and Fehmy Agha), trapezoid-shaped text columns, line art, angular shapes, and slanted lines of larger-size type visually indicate this was

15

Friedmann, A. "Introduction."

Journal of Interior Design Education and Research 1.1 (1975): p. 2. 16

Salen, K. “Editor's Note," Zed, 1 (1994): p. 6 . a periodical paving a new path. Though not to the same extent as Zed, the layouts of editor introductions within Dot Zero (1966), Octavo (1986), Fuse (1991) and Iridescent (2009) were also given consideration regarding white space and typographic variations.

The remaining texts fall in the middle of this spectrum, and are similar to one another in terms of their visual design. In this way, they maintain 
the look and feel of what periodicals and editor introductions characteristically look like: single, two- or three-column layouts with consistent margins, serif typefaces, and a tendency to make use of only a few graphic elements per page spread. To a viewer-reader, these texts may appear 'standard,' as there is little to differentiate them from the pages of any other periodical. Some subtly set themselves apart by using sans serif typefaces (see examples within Vision in the Making), italics (Graphis 1944; Dot Zero 1966), or by including graphic imagery (U\&lc 1973; Fuse 1991; Visual Communication 2002; Journal of Visual Culture 2002; The Poster 2010; Communication Design 2015), or, in one case, an editor's headshot portrait (Design Management Journal 2002). The introductions of Design Studies (1979) and Journal of Decorative and Propaganda Arts (1986) bear the signatures of their editors. Overall, these decisions may have been a result of a periodical's visual identity, a publisher's house style, or available production technology. Indeed, the assertion of particular visual characteristics and styles may have been a purposeful attempt to establish credibility and to meet expectations within the greater academic and professional communities. On the other hand, these 'standard' graphic layouts may contradict the editorial language they contain concerning innovation and new goals for design artifacts and activities.

Language also varies among the introductions. For the most part, the founding editors write to inform and make one or more emotional appeals. This approach was also used to guide the editorial and visual structure of Vision in the Making. The editors of the periodicals I have examined during my study acquaint audiences with their periodical's focus, perspective, and context. In so doing, one periodical is differentiated from the others that occupy its disciplinary landscape, and its practical function is established. Nonetheless, these texts also contain expressive language that encourages readers and entices potential contributors. The editors challenge ideas of the past while anticipating the future, and phrases such as 'we will,' 'we want,' 'the world needs,' 'our dream,' and similar permeate the introductions. Curiously, texts with more colorful language reside within 'standard' visual layouts. This includes editors' personal stories (Ergonomics in Design, 1993; The Poster, 2010; Codex: The Journal of Typography, 2011) and quirky, unexpected content (Dot Zero, 1966; Journal of Art and Design Education, 1982; Journal of Product Innovation Management, 1984). Some of these ideas were incorporated into Vision in the Making. Beyond these, two texts stand out. William Edward Rudge, the founding editor of Print (1940) alludes to an audience that is primarily male and middle-class. 
This reflects pertinent aspects of design's history, but is not included in Vision in the Making. The inaugural issue of Design Studies (1979) contains persuasive language by its first managing editor Nigel Cross befitting a speech to motivate the masses, and pieces of this are included in the new text for emphasis.

Through its narrative and bibliography, Vision in the Making reveals that certain overarching visions and issues have remained constant in periodicals devoted to chronicling, analyzing and criticizing design for over one hundred years. These include the integration of theory, history, and criticism with practice, the challenges and opportunities that attach to utilizing new technologies, and a propensity among many editors for addressing educational concerns. At the same time, editors' perspectives reflect those of the audiences to whom they speak, and these introductions are akin to snapshots of a changing history. Early twentieth century printing trade concerns have given way to today's academic, global, multicultural, economic, industrial, and social issues in design (for example, see Vision in the Making lines 26, 38, 40, 43, 57, 69, 71, 74, $83,97,105$, and 123). The editorial introductions reveal the evolution of what was a customer-centered industry into a more inclusive design community that includes and fosters critical, self-aware discourse.

Editor introductions anticipated and looked toward a future... which happens to be now: are we changing the paradigm (line 27)? Practicing in provocative ways and raising controversial issues (line 39)? Thinking deeply about design as a world-shaping force (line 77)? Questioning tradition and taking risks (line 116)? The launch of this first issue of Dialectic demonstrates that there is still new territory to investigate and document. The contents of design periodicals have certainly changed over time, yet the form of these meta-artifacts has changed little. Moreover, the design periodicals examined in this study are printed and bound or exist online in a print-friendly format, which presents yet another question: What shape or form might the future chronicles of our design knowledge take?

\section{Conclusion}

Vision in the Making is an intertextual composition of editors' introductions to first issues of design periodicals and, in effect, it manifests as an interplay of the voices that shepherd ongoing dialogue concerning what design is, does, and might become. This study forms a foundation for further inquiry about the nature of scholarship in design. It is intended to be read in a few of different ways: as an amusing narrative in its own right; as a starting point for learning titles, 
names, and dates associated with design periodicals through the bibliographic footnotes; and as a manifesto calling for awareness of the editorial voices and publication venues that have helped shape design practice and scholarship. Additionally, readers are asked to consider how close readings of other design texts might be facilitated through a similar cut-and-paste prototyping process. Ultimately, Vision in the Making strives to inspire. It demonstrates that nearly every editor's words allude to the same desire as the readers and authors - to engage in a practice through writing, theory, criticism, education, designed things, or something else entirely: 


\section{(a "provotype") \\ vision in the making}

Jessica Barness

The first issue of a new journal is a moment for celebration and a time for reflection ${ }^{1}$ (and) Our inaugural issue has no theme other than courage. ${ }^{2}$ Is this a utopian endeavour? Perhaps. ${ }^{3}$ (Our project) is not a sudden venture ${ }^{4}$ (and) it belongs to no single person or entity. ${ }^{5}$ It is always a special time when a new product is launched, a time like the dawn of a new day when the darkness of struggles past gives way to the bright hope of the future. ${ }^{6}$ (We are) on the verge of tremendous growth. ${ }^{7}$ Design has entered a golden age ${ }^{8}$ (and) there is no scarcity of fresh thinking and new idcas being generated in this ficld. ${ }^{9}$ The launch of this new journal emerges from an extraordinary range of ${ }^{10}$ vision, sweat, and perseverance. ${ }^{11}$ There are already enough constraints imposed on our ability to think and to write fresh and creative work without inventing any new ones. ${ }^{12}$ speaking against power is always dangerous and repression breeds invention in the repressed. ${ }^{13}$ Before the paint is dry on the protest poster, the issue has shified-so much has our rate of communication changed..$^{14}$ (Our project) is a springboard (...) an incitement (...) a laboratory. It is an experiment in how we think. ${ }^{15}$ As a designer (in a previous life) I was never really aware of the moral obligation imposed on me to act in a way that brought no harm to the world, let alone to promote good. ${ }^{16}$ It is time for a fresh approach. ${ }^{17}$ Good design is no longer a matter of good taste and intelligence alone, ${ }^{18}$ for all too often design is seen as a prettifying profession. ${ }^{19}$

1 Ken Friedman, Yongqi Lou, and Jin Ma, "Editorial," Shè Jì: The Journal of Design, Economics, and Innovation, 1.1 (2015): p. 1.

2 Pamela Johnson, "From the Editor," Journal of Decorative and Propaganda Arts, 1.1 (1986): p. 5.

3 Editor(s), "Editorial," Journal of Visual Culture, 1 (2002): p. 5.

4 Stuart Macdonald, "Editorial," Journal of Art and Design Education, 1 (1982): p. 2.

5 Charlie Breindahl, Ida Engholm, Judith Gregory, Erik Stolterman, "The Computer and Design," Artifact, 1 (2007): p. 3.

6 Blair Little, "The Dawn of a New Journal," Journal of Product Innovation Management, 1.1 (1984): p. 1.

7 Marty Neumeier, "Welcome," Critique, 1 (1996): n.p.

8 Elizabeth Guffey, "Editorial Introduction," Design and Culture, 1.1 (2009): p. 5.

\author{
9 Merald Wrolstad, "A Prefactory Note to the First Number," \\ Journal of Typographic Research, 1.1 (1967): n.p. Later published \\ as Visible Language. \\ 10 Editor(s), untitled, Material Culture, 1.1 (1996): p. 5 . \\ 11 Little, "The Dawn of a New Journal," 1. \\ 12 Editor(s), untitled, Material Culture, 6. \\ 13 Simon Downs, "Editorial," The Poster, 1.1 (2010): p. 6. \\ 14 Robert Malone, "Editorial," Dot Zero, 1.1 (1966): n.p. \\ 15 Editor(s), "Editorial," Journal of Visual Culture, pgs. 5-6. \\ 16 Downs, "Editorial," 6. \\ 17 John Wozencroft, "Fuse," Fuse, 1.1 (1991): n.p. \\ 18 Malone, "Editorial," n.p. \\ 19 Max Bruinsma, "Iridescent: A Prism on Design \\ Research," Iridescent, 1 (2009): p. 10. Later published \\ as Communication Design.
}


During the past three decades, there has emerged a wealth of thoughtful, mischievous, exacting and imaginative research and writing. ${ }^{20} \mathrm{Few}$ serious, critical or erudite articles appear in the professional magazines ${ }^{21}$ (and our project) has evolved from a desire to see an independent publication which acts as a serious forum for the discussion of matters, both contemporary and historical ${ }^{22}$ But, then, we never thought that doing, activating, sounding out visual culture should be anything other than awkward, thought-provoking, captivating. ${ }^{23}$ Since the early 20 th century a great deal of theoretical thinking has taken place in the context of design practice, and today this is increasingly taken up and developed in the context of academic research. ${ }^{24}$ As (our project) evolves, it will look even further afield to curate the work of men and women who spend every day of their lives creating. ${ }^{25}$ No one, least of all the designer, can operate meaningfully in today's fast-changing economic and cultural situation without a well-defined sense of purpose. ${ }^{26}$ We are changing the paradigm ${ }^{27}$ (and the) changes are shaking us to our roots. ${ }^{28}$

\section{As a hybrid journal, ${ }^{29}$ design practice (...) total design (...) design activity ${ }^{30}$ will be addressed} an educational, historical, technological or practical perspective. ${ }^{31}$ This requires research, discourse, and debate. ${ }^{32}$ Design has acquired not just a history but also a historiography. ${ }^{33}$ not only an increasing amount of critical analysis, but also of critical practice. ${ }^{34}$ There are no sharp breaks-no boundaries-- where the realm of science ends and those of the humanities and art begin. ${ }^{35}$ The formation of a new set of directions for thinking about design is a long-term project $^{36}$ (and) it will be critical that any new approaches and new solutions are inherently sustainable. ${ }^{37}$ Our project is, of necessity, a political one ${ }^{38}$ (and furthermore) The aim of this journal is to be provocative and to raise controversial issues. ${ }^{39}$ tacit knowledge, conditions for creative performance, serendipity, creativity of teams, organizational culture and entrepreneurship make up a sixpack brimfull of potential controversy. ${ }^{40}$ Design was once an art focused on the shape of things. ${ }^{41}$ Nobody today is a commercial artis! $!^{42}$ This shift is a transformation from thinking of design as a

20 Editor(s), "Editorial," Journal of Visual Culture, 5. 21 Arnold Friedmann, "Introduction", Journal of Interior Design Education and Research, 1.1 (1975): p. 2.

22 Simon Johnston, Mark Holt, Michael Burke, Hamish Muir, "86.1," Octavo, 1 (1986): n.p.

23 Editor(s), "Editorial," Journal of Visual Culture, 5.

24 Carey Jewitt, Theo Van Leeuwen, Ron Scollon, Teal Triggs,

"Editorial," Visual Communication, 1.1 (2002): p. 6.

25 John Boardley, "This Wonderful Affliction," Codex: The

Journal of Typography, 1 (2011): p. 5 .

26 Victor Margolin, "Editorial," Design Issues, 1.1 (1984): p. 3

27 Sydney Gregory, "Design Studies: The New Capability,"

Design Studies, 1.1 (1979): p. 2.

28 Neumeier, "Welcome," n.p.

29 Peter Storkerson, "From the Editor," Design Research

Quarterly, 1.1 (2006): p. 3.

30 D.F. Sheldon, "Editorial Comment," Journal of

Engineering Design, 1.1 (1990): p. 3.
31 Rachel Cooper, "Design Research Comes of Age,"

The Design Journal, 0.1 (1997): p. 1.

32 Aleksandar Subic, "Editorial," International Journal

of Sustainable Design, 1 (2008): p. 2.

33 Christopher Bailey, "Editorial," Journal of Design History, 1.1

(1998): n.p

34 Jewitt, Van Leeuwen, Scollon, and Triggs, "Editorial," 6.

35 Wrolstad, "A Prefactory Note to the First Number," n.p.

36 Margolin, "Editorial," 3.

37 Subic, "Editorial," 2.

38 Editor(s), untitled, Material Culture, 8.

39 Margolin, "Editorial," 3.

40 Susan Moger and Tudor Rickards, "Editorial," Creativity

and Innovation Management, 1.1 (1992): p. 3.

41 Friedman, Lou, and Ma, "Editorial," 2.

42 Editor(s), untitled, CA: Journal of Commercial Art, 1.1

(1959): p. 2. Later published as Communication Arts. 
craft-based artisan skill of designing things to thinking of design across a spectrum of target fields. ${ }^{43}$ The remit of the designer has necessarily broadened from the design of the visual to also include the design of sound, haptics, experiences and services. ${ }^{44}$

Those who can communicate succeed; those who can't, fail. ${ }^{45}$ the medium through which a message is communicated is as important as the message itself. ${ }^{46}$ (so) There will also be space in the journal for visual material - experimental typography, drawings, sketches for objects, ${ }^{47}$ (and) narrow questions of semantics to larger issues of identity, ${ }^{48}$ (and) what has been called 'the meaning of things' ${ }^{49}$ Our fingers are also known as "digits" (...) to be to be digital is to be radical and new..$^{50}$ instead of exposing practice as research, you could also stage, perform, curate, translate, unfold or reflect practice as research..$^{51}$ (Design,) ebbing and flowing a thousand times a day, is long overdue for a chronicle to present possessions and potentialities. ${ }^{52}$ It connects goal to strategy, image to word, style to substance. ${ }^{53}$ (and it) infiltrates almost every aspect of our visual culture. ${ }^{54}$ This dialogue on the historical, contextual, theoretical, institutional and interpretive modalities (...) will take on specific and interrelated forms. ${ }^{55}$ (These) are goals for humanity as a whole in the context of inclusive wellbeing. ${ }^{56}$ (We are) blurring the boundaries of public and privately consumed media (...) the collapsing of the creator and user into a single individual. ${ }^{57}$ What will be the shape of our new world of design 758

The growth of any discipline relies on the accumulation of knowledge..$^{59}$ (But) We have wrapped our conversations tightly around ourselves, blankets of white noise offered with expectations of sameness. ${ }^{60}$ Disciplines, with their boundary-maintaining devices, institutional structures, accepted texts, methodologies, internal debates and circumscribed areas and circumscribed areas of study tend, by virtue of their very constitution, to be rather conservative in nature. ${ }^{61}$ We have swallowed ideas and images that our grandparents would have choked on ${ }^{62}(\mathrm{We})$ remember it with mixed emotions-mainly a nostalgic association with green eye shades, garters on the sleevcs, naked light bulbs and low

\footnotetext{
43 Friedman, Lou, and Ma, "Editorial," 2.

44 Teal Triggs, "Research Notes: Communication Design,"

Communication Design, 3.1 (2015): p. 1. Continuation of Iridescent, beginning as vol. 3 .

45 Daryle Jean Gardner-Bonneau, "Comment from the

Editor," Ergonomics in Design, 1.1 (1993): p. 3.

46 Masoud Yazdani, "Editorial," Intelligent Tutoring Media, 1.1

(1990); p. 2. Later published as Digital Creativity.

47 Margolin, "Editorial," 3.

48 Editor(s), untitled, Material Culture, 8.

49 Bailey, "Editorial," n.p.

50 Editors(s), "Editorial," Digital Creativity, 8.1 (1997): p. 1.

Continuation of Intelligent Tutoring Media, beginning as vol. 8 .

51 Michael Schwab, "Editorial," Journal of Artistic Research, o.1

(2011): para. 3 .
}

52 William Rudge, "You... and the Graphic Arts,"

\author{
Print: A Quarterly Journal Of The Graphic Arts, 1.1 (1940): \\ n.p. Later published as Print. \\ 53 Neumeier, "Welcome," n.p. \\ 54 Emma Tucker, "Editor's Letter," Monotype Recorder, 1 \\ (2014): n.p. \\ 55 Editor(s), "Editorial," Journal of Visual Culture, 5. \\ 56 Friedman, Lou, and Ma, "Editorial," 4. \\ 57 Julia Knight and Alexis Weedon, "Editorial," \\ Convergence, 1.1 (1995): p. 8. \\ 58 Gregory, "Design Studies: The New Capability," 2. \\ 59 Lin-Lin Chen, "International Journal of Design: A Step \\ Forward," International Journal of Design, 1.1 (2007): p. 1. \\ 60 Katie Salen, “Editor's Note," Zed, 1.1 (1994): p. 6. \\ 61 Editor(s), untitled, Material Culture, 5. \\ 62 Malone, "Editorial," n.p.
}


nostalgic association with green eye shades, garters on the sleeves, naked light bulbs and low pay. ${ }^{63}$ No longer do we need to restrict ourselves to particular viewpoints or methodologies in order to analyse, interpret and understand the visual world around us. ${ }^{64}$

As such we have no obvious genealogy of ancestors to whom we should pay homage, and are not concerned to invent any. ${ }^{65}$ Part of our task is to trace them. ${ }^{66} \mathrm{It}$ 's what a research journal should do: filter the luster and see what it is composed of ${ }^{67}$ (so that) valuable time will not be unduly encroached upon. ${ }^{68} \mathrm{All}$ of us can contribute to building a common theoretical foundation, one which can then be passed on to future generations of designers. ${ }^{69}$

Design is a global topic, ${ }^{70}$ as both a social activity and as a subject for critical enquiry. ${ }^{71}$ as 'doers' and 'thinkers' ${ }^{72}$ call it what you wish. ${ }^{73}$ This journal has, as its over riding purpose, the creation of provision for the interchange of ideas on an international basis,${ }^{74}$ a panoramic window, a showcase (...) a clearing house for the international exchange of ideas and information. ${ }^{75}$ It will attempt to serve as an organ expressing the designer's point of view in the new scene. ${ }^{76}$ Broadly, (our project) is about getting more people to think deeply about design as a world-shaping force, be stopped in their tracks by this recognition and then to participate in developing more informed design thinking and action. ${ }^{77}$ let's go back to the drawing board and do it ${ }^{78}$ whether it has come within the range of "practical politics" from their point of view or not. ${ }^{79}$ (We may be) anglophone but not anglocentric, as we hope to show in this first issue ${ }^{80}$ The world is constituted through a continuous dynamism, ${ }^{81}$ (and) It is this spirit we hope to make visible in our journal: shared interests and concerns, distinctly different voices and approaches. ${ }^{82}$ In contrast (...) a multiplicity of voices shapes our view design and its discourse today ${ }^{83}$ (and) there are important relationships that have not been expressed and categories that overlap or defy easy classification. ${ }^{84} \mathrm{We}$ are confident that the articles, debates, interviews and reviews published in these pages will take account of the complex and inter-animating series

63 Editor(s), untitled, CA: Journal of Commercial Art, 2. 64 Jewitt, Van Leeuwen, Scollon, and Triggs, "Editorial," 5. 65 Editor(s), untitled, Material Culture, 5 .

66 Editor(s), "Editorial," Journal of Visual Culture, 5.

67 Bruinsma, "Iridescent: A Prism on Design Research," 10. 68 Editor(s), "The Monotype Recorder," The Monotype Recorder and Monthly Circular, 1.1 (1902): n.p.

69 Chen, "International Journal of Design: A Step Forward," 2.

70 Cooper, "Design Research Comes of Age," 1.

71 Paul Stiff, “Typography papers," Typography papers, 1

(1996): n.p.

72 Schwab, "Editorial," para. 10

73 Editor(s), untitled, CA: Journal of Commercial Art, 2.

74 John Heywood, "Editorial," International Journal

of Technology and Design Education, 1.1 (1990): p. 2.
75 Herb Lubalin, Aaron Burns, Ed Rondthaler, Jack Anson Finke, "Why U\&lc?" UElc, 1.1 (1973): p. 2.

76 John Hallas, “Introduction," Icographic, 1.1 (1971): p. 1.

77 Anne-Marie Willis, "Opening Lines on Unsustainability,"

Design Philosophy Papers, 1.1 (2003): p. 1.

78 Editor(s), untitled, CA: Journal of Commercial Art, 2.

79 Editor(s), "The Monotype Recorder," 1-2.

80 Stiff, "Typography papers," n.p.

81 Editor(s), untitled, Material Culture, 6.

82 Jewitt, Van Leeuwen, Scollon, and Triggs, "Editorial," 5.

83 Guffey, "Editorial Introduction," 6.

84 Merald Wrolstad, "Visible Language: The Journal for

Research on the Visual Media of Language Expression,"

Visible Language, 5.1 (1971): p. 5. Continuation of Journal

of Typographic Research. 
of relations that exist between history, theory and practice ${ }^{85}$ After all, any journal article is not the research, but a deliberately created (re)presentation of research within a restricted format. ${ }^{86}$ (There are) New materials, new tools, new ways to plan work ${ }^{87}$ (and) Design is no exception. ${ }^{88}$ We have a world to win. ${ }^{89}$

The best design is done with intensity and commitment and ${ }^{90}$ The success of any journal is dependent on the success of the community it aims to serve. ${ }^{91}$ (This project) is, then, for academics, scholars, students, and practitioners struggling with the questions, the challenges, and the possibilities ${ }^{92}$ because design research is dispersed in journals across many different fields, it is difficult for design researchers to locate and read each other's works, ${ }^{93}$ challenging conventional theories of representation. ${ }^{94}$ The very breadth of the discipline, however, is problematic; ${ }^{95}$ But the whole field is dissociated, its energies uncoordinated, its efforts unencouraged, its voice inarticulate. ${ }^{96}$ At the same time, as design programs proliferate throughout the United States, many educators have realized that design education lacks the dimension of history, theory, and criticism that can foster more sophisticated and critical responses to new situations. ${ }^{97}$ Consequently, designers speak to other designers, academics to other academics, and students to no one in particular, or any who might listen. ${ }^{98}$ It would be presumptuous to say that (this project) has been created to solve this problem ${ }^{99}$ (but) We intend to live up to your high expectations. ${ }^{100}$ (This project) is a kind of experiment in which we hope to accommodate many possibly discordant voices ${ }^{101}$ (and) Plans made for an uncertain future can now begin to take on solid form..$^{102}$

(We) must keep continually alert to new research in every related area, and the best internal communication channel for new ideas is an active, vocal readership ${ }^{103}$ in the context of protectable intellectual property ${ }^{104}$ that is historical/futuristic/comparative/ qualitative/quantitative/ethnographic/ethics-based/practice-led. ${ }^{105}$ (This) has often had a neurotic edge, which presents in obsessive formalisms, and in the self-satisfaction

85 Editor(s), "Editorial," Journal of Visual Culture, 6. 86 Schwab, "Editorial," para. 8.

87 Lubalin, Burns, Rondthaler, and Finke, "Why U\&lc?" 2. 88 Chen, "International Journal of Design: A Step Forward," 1. 89 Gregory, "Design Studies: The New Capability," 2. 90 Margolin, "Editorial," 3. 91 Yazdani, "Editorial," 2.

92 Editor(s), "Editorial," Journal of Visual Culture, 6.

93 Chen, "International Journal of Design: A Step Forward," 1. 94 Michael Bull, Paul Gilroy, David Howes and Douglas Kahn, "Introducing Sensory Studies," The Senses and Society, 1.1 (2006): p. 5 .

95 Thomas Walton, "Design Management as a Business and Academic Discipline," Design Management Journal, 1.1 (2000): p. 5 .
96 Rudge, "You... and the Graphic Arts," n.p.

97 Margolin, "Editorial," 3.

98 Salen, "Editor's Note," 6.

99 Margolin, "Editorial," 3.

100 The Editors, “Welcome," How, 1.1 (1985): p. 19.

101 Stephen Scrivener, "Editorial," CoDesign, 1.1 (2005): p. 2.

102 The Publishers, "Introducing Graphis," Graphis, 1.1

(1944): p. 3.

103 Wrolstad, "A Prefactory Note to the First Number," n.p.

104 Moger and Rickards, "Editorial," 2.

105 Omar Vulpinari, "The Essentials," Iridescent, 1

(2009): p. 9. Later published as Communication Design. 
of the comfortable just as much as in the self-inflation of the nouvelle. ${ }^{106}$ we particularly encourage debate, ${ }^{107}$ provocation and contestation, ${ }^{108}$ to create a centre for discussion which which at present occurs, if it occurs at all, on the margins. ${ }^{109}$ And so the margins grow ${ }^{110}$ in the form of editorial notes on 'burning issues' that are worth printing and that meet the aims of the journal. ${ }^{111} \Lambda t$ the same time, if you take issue with anything, let us hear about it !112

the concept for this journal was borne out of a perceived gap, or margin, in the current design dialogue. ${ }^{113}$ Not quite as exciting as the arrival of one's first child, I guess ${ }^{114}$ (but) The offspring is in your hands, and its growth and nurturance are largely up to you. ${ }^{115}$ The best way to encourage a new generation of (...) designers is to break open (the) closed circle, to question its traditions and to support risk taking. ${ }^{116}$ not enough progress has yet been made to shift from a teacher-led environment to one enabling a student-focused approach. ${ }^{117}$ its future depends upon their continued interest and writings, or as a harassed editor should say, upon their typings, triplicate, one-sided, marginate, and double-spaced. ${ }^{118}$ Although (we) worked long and hard, (we) saw the stars and (we) had the pleasure of an inherently satisfying task-building something new while aspiring to serve others. ${ }^{119}$ Following this short celebration, we will turn the pages of (this project) over to thinkers whose work has helped to define the design field today, building bridges to inno vation, value creation, the productive economy, and the world we build together. ${ }^{120}$ This journal is one of the first of its kind ${ }^{121}$ (yet) It is simply a beginning-a concept that will ideally grow and transform as needs are identified and new energies explored. ${ }^{122}$ (It is) is a lens through which emerging discourses in contemporary communication design research and professional practices are made manifest, critically examined and developed. ${ }^{123}$ (It) does not need to be an 'ultimate statement', 124 There is nothing here intended to be final or definitive; 125 a new level of thinking is not expected to emerge full-blown like Athena from the head of Zeus. ${ }^{126}$ We hope you enjoy our first issue. ${ }^{127}$ It is a start. ${ }^{128}$

106 Stiff, "Typography papers," n.p.

107 Storkerson, "From the Editor," 3.

108 Editor(s), "Editorial," Journal of Visual Culture, 5.

109 Bailey, "Editorial," n.p.

110 Salen, "Editor's Note," 6.

111 Sheldon, "Editorial Comment," 3.

112 Wrolstad, "A Prefactory Note to the First Number," n.p.

113 Salen, "Editor's Note," 6.

114 Scrivener, "Editorial," 1.

115 Gardner-Bonneau, "Comment from the Editor," 3.

116 Wozencroft, "Fuse," n.p.

117 Editor(s), "Editorial," Art, Design, and Communication

in Higher Education, 1.1 (2002): p. 5.
118 Macdonald, "Editorial," 2.

119 Little, "The Dawn of a New Journal," 1.

120 Friedman, Lou, and Ma, "Editorial," 1.

121 Sheldon, "Editorial Comment," 3.

122 Salen, "Editor's Note," 12.

123 Triggs, "Research Notes: Communication Design," 1.

124 Wozencroft, "Fuse," n.p.

125 Malone, "Editorial," n.p.

126 Margolin, "Editorial," 3.

127 Walton, "Design Management as a Business

and Academic Discipline," 7.

128 Scrivener, "Editorial," 4. 


\section{References}

Baker, S. “A Poetics of Graphic Design?” Visible Language, 28.3 (1994): pgs. 245259. Available at: http://search.proquest.com/docview/1297966689?accountid=11835. Online. (Accessed 20 September 2016).

Barness, J. "Letters are Media, Words are Collage: Writing Images through A (Dis)Connected Twenty-Six.” Message, 2 (2015): pgs. 46-53. Online. Available at: http://www.jessicabarness.com/papers/Barness_Disconnected26_Message2015.pdf (Accessed 20 September 2016).

Boer, L. \& Donovan, J. 2012. "Provotypes for Participatory Innovation" in DIS 2012: Proceedings of the Designing Interactive Systems Conference, 11-15 June 2012, Newcastle, UK: ACM press, 2012: pgs. 388-397. Online. Available at: http://dx.doi.org/10.1145/2317956.2318014 (Accessed 20 September 2016).

Buckley, C. "Made in Patriarchy: Toward a Feminist Analysis of Women and Design.” Design Issues, 3.2 (1986): pgs. 3-14. Online. Available at: http://www.jstor.org/stable/1511480 (Accessed 20 September 2016).

Dilnot, C. “The State of Design History, Part I: Mapping the Field." Design Issues, 1.1 (1984): pgs. 4-23. Online. Available at: http://www.jstor.org/ stable/1511539 (Accessed 20 September 2016).

Drucker, J. Figuring the Word: Essays on Books, Writing, and Visual Poetics. New York, NY, USA: Granary Press, 1998.

Editors. "Welcome." How, 1.1 (1985): pg. 19.

Fallan, K. \& Lees-Maffei, G. "It's Personal: Subjectivity in Design History." Design and Culture, 7.1 (2015): pgs. 5-27. Online. Available at: http:// www.tandfonline.com/doi/abs/10.2752/175470715X14153615623565 (Accessed 20 September 2016).

Friedmann, A. "Introduction." Journal of Interior Design Education and Research, 1.1 (1975): p. 2.

Gemser, G., de Bont, C., Hekkert, P., \& Friedman, K. “Quality perceptions of design journals: The design scholars' perspective.” Design Studies, 33.1 (2012): pgs. 4-23. Online. Available at: http://dx.doi.org/10.1016/j.destud.2011.09.001 (Accessed 20 September 2016).

Johnston, S., Holt, M., Burke, M., \& Muir, H. “86.1.” Octavo 1 (1986): n.p. Margolin, V. “Editorial.” Design Issues, 1.1 (1984): p. 3. Online. Available at: http://www.jstor.org/stable/1511538 (Accessed 20 September 2016). 
Margolin, V. The Politics of the Artificial: Essays on Design and Design Studies. Chicago, IL, USA: University of Chicago Press, 2002.

Salen, K. “Editor’s Note," Zed, 1 (1994): pgs. 6-13.

Ruecker, S. "A Brief Taxonomy of Prototypes for the Digital Humanities.” Scholarly and Research Communication, 6.2 (2015). Online. Available at: http://src-online.ca/index.php/src/article/view/222/415 (Accessed 20 September 2016).

Vignelli, M. “Keynote Address.” In Coming of Age: The First Symposium on the History of Graphic Design, April 20-21, 1983, Rochester Institute of Technology, edited by B. Hodik \& R. Remington, pgs. 8-11. Rochester, NY, USA: Rochester Institute of Technology, 1985.

\section{Biography}

Jessica Barness is an Assistant Professor in the School of Visual Communication Design at Kent State University. Her research resides at the intersection of design, humanistic inquiry, and interactive systems, investigated through a critical, practice-based approach. She has presented and exhibited her work internationally, and has published research in Design and Culture, Visual Communication, SEGD Research Journal: Communication and Place, and Message, among others. Recently, she co-edited (with Amy Papaelias) a special issue of Visible Language journal, "Critical Making: Design and the Digital Humanities". She has an MFA in Design from the University of Minnesota, Twin Cities. jbarness@kent.edu, jessicabarness.com 